\title{
28 Research Square \\ Healthcare professionals' experience of performing digital care visits - a scoping review
}

leva Lampickienè

Karolinska Institute

Nadia Davoody ( $\sim$ nadia.davoody@ki.se)

Karolinska Institute

\section{Research Article}

Keywords: digital care visit, online consultation, medical staff, healthcare personnel, user experience

Posted Date: January 7th, 2022

DOI: https://doi.org/10.21203/rs.3.rs-1224907/v1

License: (c) (i) This work is licensed under a Creative Commons Attribution 4.0 International License. Read Full License

Version of Record: A version of this preprint was published at Life on June 17th, 2022. See the published version at https://doi.org/10.3390/life12060913. 


\section{Abstract}

Background: The use of patient initiated digital care visits has been increasing and even more so in the era of the Coronavirus (COVID-19) pandemic. Learning more about healthcare professionals' experience of using such technology would provide valuable insight and a basis for improvement of digital visits.

Aim: This study sought to explore the existing literature on healthcare professionals' experience of performing digital care visits.

Methods: A scoping review was performed following Arksey \& O’Malley's proposed framework and utilizing the Preferred Reporting Items for Systematic reviews and Meta-Analyses - Extension for Scoping Reviews (PRISMAScR) checklist. Three large databases - PubMed, Web of Science and IEEE Xplore were searched, and 28 studies were included in the review. The collected data was analyzed using thematic content analysis.

Results: Five main themes were identified in the literature: positive experiences/benefits, facilitators, negative experiences/challenges, barriers, and suggestions for improvement. Healthcare professionals mostly reported having overall positive experience with digital visits and saw benefits for themselves and the patients - efficiency, convenience, accessibility, and new perspectives in remote care to name a few. However, opinions were mixed or negative regarding the complexity of decision making, workload and workflow, suitability of this type of care and other challenges. The suggestions for improvement included training and education, improvements within system and tools and support for professionals.

Conclusion: Despite overall positive experience and benefits for both professionals and patients, clinicians reported challenges and issues they faced when using digital care visits: physical barriers, technical issues, suitability concerns and others. Digital care visits could not fully replace face-to face visits.

\section{Background}

Currently, Information and Communications Technology (ICT) plays a significant role in all industries and people's everyday lives. The healthcare field is no exception - medical institutions have been using advanced ICT for health records, telemedicine, various forms of e-learning and other tools. The increasing accessibility to the Internet and smart devices along with digitalization of communication influenced the application and implementation of telemedicine as a new way of providing healthcare services. (1)

One of the concepts used in today's health care is videoconferencing. (2) The concept of videoconferencing is often described in different terms such as video meetings, (3) digital/virtual meetings, digital visits, (4) or video teleconferencing. (5) The concept is rather broad - it includes consultations not only between patients and healthcare professionals, (6) but also consultations between two or more healthcare professionals or even consultations in which a patient is present with a healthcare professional on a clinical site or their home and together they are consulted by a specialist from another clinical site. $(7,8)$ In this review a narrower concept of videoconferencing is considered central - video consultations initiated by patients in which they are consulted by health care professionals. This type of consultation is referred to differently in the literature - sometimes as videoconferencing $(9,10)$ despite that it is broader than just patient-to-healthcare professional consultations, virtual visits, (11) telehealth which can mean both telephone and video consultations, $(12,13)$ digital visits, or video consultations (13) to name a few. 
The use of video consultations has been greater than ever. It is important to note that despite their advantages such as providing timely care to patients in rural areas or to home bound chronically ill patients, adoption and implementation of digital care visits accelerated during the last year due to the unprecedented phenomenon of the COVID-19 pandemic. While not being the only factor to drive the adoption of digital care visits, it still played a significant role in the process. Due to the widespread infection most of the countries implemented public restrictions and recommendations such as minimizing or banning gatherings, countrywide lockdowns, social distancing, wearing protective masks and paying special attention to hand hygiene to control the contagion. (14) The infection rates were increasing exponentially during the first and second waves of the pandemic and there were large numbers of severely ill patients that needed immediate hospitalization and even intensive care. (14) This resulted in an unusually high workload for the healthcare sector - multiple wards in the hospitals were transformed into COVID-19 wards due to the shortage of beds in intensive care units (ICUs), health personnel have been working tirelessly to help those in need. (15-17) The situation was so severe, that routine visits and other non-emergency procedures had to be postponed, prioritizing COVID-19 patients and putting all the other patients on hold. $(14,17)$

Health care institutions were forced by the circumstances to rapidly adopt and implement digital care visits in their practice to provide telemedicine services. $(18,19)$ The urgency of the situation sped up the process of authorization and regulation regarding legal matters such as new payment models for remote health care services and health information privacy. (19) Digital care visits got implemented in various areas of health care - primary care, mental health, $(20,21)$ orthopedic care, $(22)$ neurology, $(18,23,24)$ palliative care, $(25)$ pharmacy, $(26)$ dentistry, $(27)$ and others. Even though digital care visits do not provide possibilities for physical examinations where a healthcare professional would need to physically examine a patient, video consultations allow specialists to evaluate and sometimes diagnose by inspecting the patient through video. The pandemic has brought massive challenges and burdens to this world, but it also stimulated people to adapt and seek for quick and creative solutions, therefore speeding up the implementation of technology in different areas including the health care sector.

Some research has been done regarding the use of video conferencing, implementation issues, policies etc (11) and also patients' experience and perceptions of using videoconferencing for healthcare visits, $(6,28-30)$ however, the number of studies on healthcare professionals' experience with patient initiated digital visits is limited.

A broader overview including healthcare professionals from different specializations and the latest literature could contribute to a better understanding of what is known on this topic, what are the research gaps and what should be studied more. Finding out what are the benefits and challenges of using digital care visits from the healthcare professionals' perspective could be helpful in optimizing the service for both health workers and patients, making it safer and more usable resulting in higher satisfaction with the service as well as more efficient use of limited healthcare staff resources.

\subsection{Aim}

The aim of this study is to explore the exiting literature on user experience of using digital care visits from different healthcare professionals' point of view.

\section{Methods.}

A scoping review design was chosen for this study. The scoping review was conducted using the methodological framework by H. Arksey and L. O'Malley (31) as well as adapted PRISMA-ScR checklist by Tricco et al. (32) 


\subsection{Search strategy and timeframe}

Specific search terms and their combinations for finding the literature were thoroughly researched and tested. The search terms were then adjusted to retrieve the most relevant studies that fall under the scope of the selected topic, and the queries were adapted to match each chosen database's syntax. Three databases were chosen for the search: PubMed, Web of Science, and IEEE Xplore. The search queries used for the selected databases are presented in Table - 1). The filters applied for the searches were 10 years' time span, English language, and full text available.

Aside from the database search, grey literature ("includes a range of documents not controlled by commercial publishing organizations") (33) was searched using similar search terms through Google Scholar and reviewing the reference lists of included studies to identify literature that has not been formally published in scientific journals. Manuscripts that were not yet published, conference papers, dissertations, governments documents and other types of grey literature (34) were searched for and screened for eligibility. The search was carried out during the period of 01032021 - 15042021.

\subsection{Study selection}

The literature was screened for eligibility based on inclusion and exclusion criteria. The inclusion criteria were original articles, conference proceedings, review articles and reports published within the last 10 years, language English, focused on healthcare professionals' experience of using digital care visits for patient consultations. Papers that fell under the scope and were published within specified time frame and were retrieved during the "grey literature" search, were also included. The exclusion criteria were articles published in other languages than English, earlier than 2011 and focused on patients' experience of using digital care visits or covering healthcare professionals' willingness to use of digital care visits rather than experience of using it.

For this review a total of 1440 studies were retrieved, 44 duplicates were removed - more detailed numbers can be found in the flowchart (Figure - 1.) Citations were handled using the referencing program Mendeley. The initial screening was performed by reading the titles and abstracts of the retrieved results. After the screening 97 studies qualified to the next round and were read in full to decide which to include in the review - 28 studies met the inclusion criteria and were deemed eligible for this study. Studies focusing on remote consultations via phone, asynchronous telemedicine using store and forward technology, clinician attitudes towards telemedicine or willingness to use it, healthcare professionals' experience of using telemedicine for professional-to-professional consultations, and remote monitoring were excluded. Studies which explored healthcare professionals' and patients' or caregivers' experience with digital care visits were included in the review if it was possible to separate clinicians' experience from the results. Papers in which healthcare professionals' experience of using several kinds of methods for providing telemedicine were studied, but it was possible to separate the experience with digital care visits - were deemed eligible for the review.

\subsection{Data analysis}

All 28 studies combined were read again, the information was charted in an MS Excel spreadsheet. Details such as title, publication date, study design, what kind of healthcare professionals participated in the study, country/region, main findings, and other relevant information were recorded in the spreadsheet. The emergent themes were presented in the results. 
All the collected information was analyzed using thematic content analysis, and several themes had emerged including positive experiences/advantages, facilitators, negative experiences/challenges, barriers and possible improvements of using digital care visits from healthcare professionals' experience. The themes were divided into categories and then subcategories that explain the findings in more detail.

\subsection{Ethical considerations}

Ethical issues were considered for this study, however due to the nature of this study, no human subjects were involved. The data analyzed in this review is published articles and reports that are freely or institutionally accessible. No sensitive data such as real medical records were used, meaning that there were no ways to harm anyone's integrity.

\section{Results}

\subsection{General characteristics of the reviewed studies}

Most of the selected studies were published in the last 5 years while only one study was published earlier - in 2015. More than two thirds of the included papers were recent - published in 2020 or 2021 . The studies were carried out in different countries - Australia $(n=4)$ and Europe $(n=10)$ while half of the studies originated from the United States of America $(n=14)$. More than a half of the studies explored experiences of physicians among which were medical oncology professionals, $(35,36)$ general practitioners, $(13,37-39)$ otolaryngologists, $(40)$ urologists, (41) cardiologists, $(42)$ and sport medicine professionals - physiatrists. $(43,44)$ Another considerable group of professionals was mental health professionals - therapists and psychotherapists - who participated in eight studies. Other healthcare professionals' such as nurses', advanced practice professionals', dieticians', physical therapists' experience was studied in nine papers. Non-medical professionals, patients and caregivers were included in some studies; however, their experiences were clearly separated in the results and findings regarding their experience were not included in this review. Fifteen studies were related to the ongoing COVID-19 pandemic (Table 2). 
Table 1

- Search strategy and the number of papers retrieved from the databases

\begin{tabular}{|c|c|c|}
\hline Database & Search words & $\begin{array}{l}\text { Number } \\
\text { of } \\
\text { papers }\end{array}$ \\
\hline \multirow[t]{3}{*}{ PubMed } & $\begin{array}{l}\text { ("digital visit*"[TIAB] OR "remote visit*"[TIAB] OR "remote consult*"[TIAB] OR } \\
\text { teleconsultation[TIAB] OR "online consult*"[TIAB] OR "video consult*"[TIAB] OR } \\
\text { videoconferencing[MH] OR videoconferencing[TIAB] OR "digital consult*"[TIAB] OR e- } \\
\text { consultation*[TIAB] OR "electronic visit"[TIAB] OR "virtual visit"[TIAB]) }\end{array}$ & \multirow[t]{3}{*}{$n=122$} \\
\hline & $\begin{array}{l}\text { AND ("medical professional*"[TIAB] OR "medical staff*"[MH] OR "medical staff*"[TIAB] } \\
\text { OR "health personnel*"[TIAB] OR "health personnel*"[MH]) }\end{array}$ & \\
\hline & AND (experience*[TIAB] OR “user experience*"[TIAB] OR “user satisfaction"[TIAB]) & \\
\hline \multirow[t]{3}{*}{$\begin{array}{l}\text { Web of } \\
\text { Science }\end{array}$} & $\begin{array}{l}\text { TS=("digital visit*" OR "remote visit*" OR "remote consult*" OR teleconsultation OR } \\
\text { "online consult*" OR "video consult*" OR "electronic visit*" OR "virtual visit*" OR } \\
\text { "telemedicine*" OR "telehealth*" OR videoconferenc* OR e-consult* OR e-health) }\end{array}$ & \multirow[t]{3}{*}{$\begin{array}{l}n= \\
1289\end{array}$} \\
\hline & $\begin{array}{l}\text { AND TS }=(\text { "medical professional*" OR "medical staff*" OR "health* personnel" OR } \\
\text { physician* OR nurs* OR therapist* OR midwi* OR "health* professional" OR "dentist*" } \\
\text { OR "caregiver*" OR "pharmacist*") }\end{array}$ & \\
\hline & AND TS=(experience* OR “user experience*" OR "user satisfaction") & \\
\hline \multirow[t]{3}{*}{$\begin{array}{l}\text { IEEE } \\
\text { Xplore }\end{array}$} & 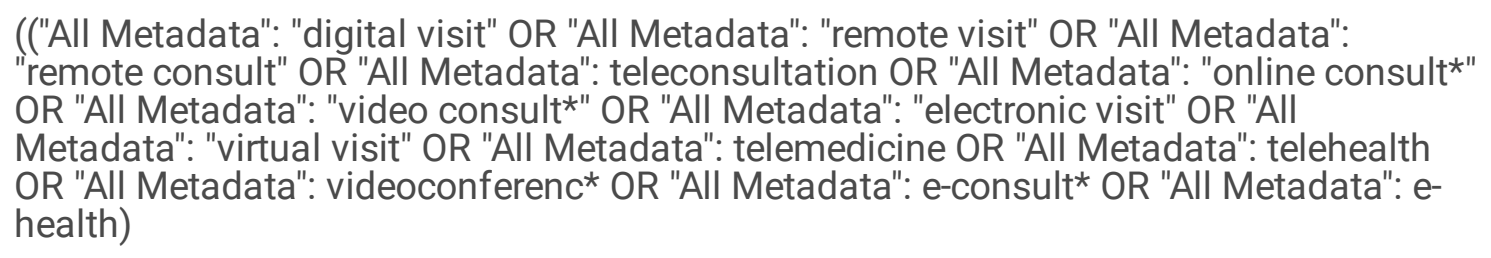 & \multirow[t]{3}{*}{$\mathrm{n}=59$} \\
\hline & $\begin{array}{l}\text { AND ("All Metadata": "medical professional" OR "All Metadata": "medical staff" OR "All } \\
\text { Metadata": "health personnel" OR "All Metadata": "health professional" OR "All } \\
\text { Metadata": physician OR "All Metadata": nurs OR "All Metadata": therapist OR "All } \\
\text { Metadata": midwi* OR "All Metadata": dentist OR "All Metadata": caregiver OR "All } \\
\text { Metadata": pharmacist) }\end{array}$ & \\
\hline & $\begin{array}{l}\text { AND ("All Metadata": experience* OR "All Metadata": "user experience" OR "All } \\
\text { Metadata": "user satisfaction")) }\end{array}$ & \\
\hline
\end{tabular}


Table 2

General characteristics of the included studies

\section{Characteristics}

Year of publication

2021

2020

2019

2018

2017

2015

Country

Australia

Belgium

France

Italy

Norway

Sweden

The Netherlands

USA

Worldwide

Methodology/type

Qualitative study - semi-structured interviews

Qualitative study - Focus groups

Web-based survey

Randomized controlled trial

Descriptive study

Observational survey

Mixed methods study

Design thinking - customer journey

Review

Study participants
Number of studies

Reference number

$\begin{array}{ll}n=13 & \begin{array}{l}(38-40,43,46- \\ 50,54,57,59,61)\end{array} \\ n=9 & (13,35,37,41,42,44,45,53,60) \\ n=2 & (36,58) \\ n=1 & (52) \\ n=2 & (51,56) \\ n=1 & (55)\end{array}$

$\begin{array}{ll}\mathrm{n}=3 & (36,50,51) \\ \mathrm{n}=1 & (42) \\ \mathrm{n}=1 & (40) \\ \mathrm{n}=1 & (45) \\ \mathrm{n}=2 & (38,56) \\ \mathrm{n}=3 & (13,37,39) \\ \mathrm{n}=2 & (50,53) \\ \mathrm{n}=14 & (35,43,44,46- \\ \mathrm{n}=2 & (41,60)\end{array}$

$\mathrm{n}=5$

$(35,36,39,51,57)$

$\mathrm{n}=1$

$\mathrm{n}=11$

$(13,38,40,41,43-45,58)$

$\mathrm{n}=1$

$\mathrm{n}=1$

$\mathrm{n}=1$

$\mathrm{n}=5$

$(35,46-48,58)$

$n=1$

$\mathrm{n}=1$

(50) 


\begin{tabular}{|lll|}
\hline Characteristics & $\begin{array}{l}\text { Number } \\
\text { of studies }\end{array}$ & Reference number \\
\hline Mental health professionals & $\mathrm{n}=8$ & $(36,45-47,50,58-60)$ \\
\hline Physicians & $\mathrm{n}=15$ & $\begin{array}{l}(13,35,37- \\
44,49,52,54,55,61)\end{array}$ \\
\hline Surgeons & $\mathrm{n}=1$ & $(53)$ \\
\hline $\begin{array}{l}\text { Nurses/nurse assitants/advanced practice } \\
\text { professionals/residents/physical therapists/speech pathologists } \\
\text { etc }\end{array}$ & $\mathrm{n}=8$ & $(36,42,48,49,51,55-57)$ \\
\hline Patients and/or caregivers & $\mathrm{n}=7$ & $(40,43,52,53,55,56)$ \\
\hline $\begin{array}{l}\text { Non-medical professionals (education staff, IT workers, social } \\
\text { workers, care coordinators) }\end{array}$ & $\mathrm{n}=4$ & $(36,43,49,55)$ \\
\hline Studies related to CoVID-19 pandemic & $\mathrm{n}=15$ & $(35,36,40-50,54,59,60)$ \\
\hline
\end{tabular}

Five major themes emerged from the data - positive experiences/benefits, facilitators, negative experiences/challenges, barriers and possible improvements of digital care visit. Each of these themes had multiple categories and subcategories. The categories will be used as subheadings further on, the results related to each of them will be presented and explained in more detail. (Tables 3, 4, and 5) 
Table 3

Positive experiences/advantages and facilitators of the digital care visits use

\begin{tabular}{|c|c|c|c|}
\hline Theme & Category & Subcategory & Reference \\
\hline \multirow[t]{21}{*}{$\begin{array}{l}\text { Positive } \\
\text { experiences/advantages }\end{array}$} & $\begin{array}{l}\text { Benefits of } \\
\text { remote work }\end{array}$ & $\begin{array}{l}\text { Flexibile working hours and/or } \\
\text { place }\end{array}$ & $(13,37,39,45-47)$ \\
\hline & & Saved travel time/costs & $(39,41,47)$ \\
\hline & & $\begin{array}{l}\text { Feeling more relaxed and at } \\
\text { ease }\end{array}$ & $(39,45)$ \\
\hline & & Convenience & $(46,47)$ \\
\hline & & Reduced workload & $(37,39)$ \\
\hline & Efficiency & Shorter visits & $(13,48,49,54)$ \\
\hline & & Increased productivity/efficiency & $(35,37,39,41,45,48,50,51)$ \\
\hline & Satisfaction & Overall positive experience & $\begin{array}{l}(13,35,40,41,43,44,46,47,49,51- \\
54)\end{array}$ \\
\hline & & Easy to learn how to use & $(41,44)$ \\
\hline & & Easy to use & $(13,39,41-43,47,49,51,53-56)$ \\
\hline & & $\begin{array}{l}\text { Satisfaction with the } \\
\text { system/platform and/or its } \\
\text { features }\end{array}$ & $(13,47,48,52)$ \\
\hline & & $\begin{array}{l}\text { Comfortable to treat patients via } \\
\text { digital care visits }\end{array}$ & $(39,48)$ \\
\hline & & $\begin{array}{l}\text { The interaction between } \\
\text { healthcare professional and } \\
\text { patient was } \\
\text { satisfactory/effective }\end{array}$ & $(39,43,49,52,53)$ \\
\hline & $\begin{array}{l}\text { Convenient, } \\
\text { accessible } \\
\text { care and } \\
\text { saved } \\
\text { resources } \\
\text { for patients }\end{array}$ & Increased flexibility & $(13,39,47,51,57,58)$ \\
\hline & & Greater accessibility & $(13,39,41,47,51,52,57,59)$ \\
\hline & & Convenience & $(46,52)$ \\
\hline & & $\begin{array}{l}\text { Reduced costs and/or time for } \\
\text { traveling }\end{array}$ & $(13,47,51,52,57-59)$ \\
\hline & & Eliminated other costs & $(52,57,58)$ \\
\hline & & $\begin{array}{l}\text { Protection from communicable } \\
\text { diseases }\end{array}$ & $(39,57)$ \\
\hline & & $\begin{array}{l}\text { Family inclusion and/or } \\
\text { education }\end{array}$ & $(57,57)$ \\
\hline & & Proper care for patients & $(39,41,52)$ \\
\hline
\end{tabular}




\begin{tabular}{|c|c|c|c|}
\hline \multirow[t]{4}{*}{ Theme } & Category & Subcategory & Reference \\
\hline & $\begin{array}{l}\text { Patients' } \\
\text { emotional } \\
\text { state }\end{array}$ & Reduced stress, empowerement & $(39,46,47,50-52)$ \\
\hline & & $\begin{array}{l}\text { Confidence and increased } \\
\text { cooperation }\end{array}$ & $(46,47,51,56)$ \\
\hline & $\begin{array}{l}\text { Patient } \\
\text { satisfaction }\end{array}$ & Satisfaction with digital care & $(37,38,49,61)$ \\
\hline \multirow[t]{19}{*}{ Facilitators } & $\begin{array}{l}\text { New } \\
\text { perspectives } \\
\text { in remote } \\
\text { care }\end{array}$ & $\begin{array}{l}\text { Ability to get instant non-verbal } \\
\text { feedback }\end{array}$ & (51) \\
\hline & & Ability to intervene in real time & (58) \\
\hline & & $\begin{array}{l}\text { Focusing on what is most } \\
\text { important }\end{array}$ & $(50,51)$ \\
\hline & & Less demanding & $(39,51)$ \\
\hline & & Increased personal safety & $(39,47)$ \\
\hline & & $\begin{array}{l}\text { Observing themselves on video } \\
\text { is helpful }\end{array}$ & (59) \\
\hline & & $\begin{array}{l}\text { Insight into patient's home } \\
\text { environment }\end{array}$ & $(35,39,46,47,58)$ \\
\hline & & More frequent visits & $(47,50,57)$ \\
\hline & & Continuity of care & $(46,47)$ \\
\hline & & More personal visits & (51) \\
\hline & & Visits can be intimate & (59) \\
\hline & & $\begin{array}{l}\text { Better than phone call } \\
\text { consultations }\end{array}$ & $(13,56)$ \\
\hline & $\begin{array}{l}\text { Technical } \\
\text { qualities }\end{array}$ & $\begin{array}{l}\text { Video and audio quality is } \\
\text { acceptable/good }\end{array}$ & $(13,37,38,43,49,51,53,55)$ \\
\hline & & No connectivity issues & (53) \\
\hline & $\begin{array}{l}\text { Possibilities } \\
\text { of digital } \\
\text { care visits }\end{array}$ & $\begin{array}{l}\text { Possiblity to } \\
\text { consult/examine/diagnose/treat } \\
\text { patients }\end{array}$ & $(35,39,43,46,49,52,55,58)$ \\
\hline & & $\begin{array}{l}\text { Possibility to work with patients } \\
\text { emotions }\end{array}$ & (59) \\
\hline & & $\begin{array}{l}\text { Possibility to build rapport with } \\
\text { patients }\end{array}$ & $(46,47)$ \\
\hline & & $\begin{array}{l}\text { The relationship with patients } \\
\text { was authentic }\end{array}$ & $(49,60)$ \\
\hline & Suitability & $\begin{array}{l}\text { Suitable for delivering } \\
\text { sensitive/bad news }\end{array}$ & (48) \\
\hline
\end{tabular}




\begin{tabular}{|c|c|c|c|}
\hline Theme & Category & Subcategory & Reference \\
\hline & & Suitable for follow-up visits & $(38,40,45,53)$ \\
\hline & & $\begin{array}{l}\text { Suitable to treat mental health } \\
\text { problems }\end{array}$ & $(38,39)$ \\
\hline & & $\begin{array}{l}\text { Suitable for treating some skin } \\
\text { conditions }\end{array}$ & $(39,57)$ \\
\hline & & $\begin{array}{l}\text { Suitable for administrative } \\
\text { purposes }\end{array}$ & (38) \\
\hline & & $\begin{array}{l}\text { Physical contact was not } \\
\text { necessary }\end{array}$ & $(40,53)$ \\
\hline & & $\begin{array}{l}\text { Suitable for chronic disease } \\
\text { management }\end{array}$ & (40) \\
\hline & & Suitable for palliative care & (35) \\
\hline & & Suitable for pediatric care & (35) \\
\hline
\end{tabular}


Table 4

Negative experiences/challenges and barriers of the digital care visits use

\begin{tabular}{|c|c|c|c|}
\hline Theme & Category & Subcategory & Reference \\
\hline \multirow[t]{21}{*}{$\begin{array}{l}\text { Negative } \\
\text { experiences/ } \\
\text { Challenges }\end{array}$} & $\begin{array}{l}\text { Complicated decision } \\
\text { making }\end{array}$ & $\begin{array}{l}\text { Difficulties making decissions } \\
\text { regarding patient's diagnosis, } \\
\text { treatment or referrals }\end{array}$ & $(13,37-39,47,53,54)$ \\
\hline & & $\begin{array}{l}\text { Difficulties in guiding the right } \\
\text { patients to digital care visits }\end{array}$ & $(13,37,39)$ \\
\hline & & $\begin{array}{l}\text { The need to rely on patient's } \\
\text { observations and descriptions }\end{array}$ & $(35,39,51,57,59)$ \\
\hline & $\begin{array}{l}\text { Clinicians' } \\
\text { professional } \\
\text { competence } \\
\text { developmet }\end{array}$ & $\begin{array}{l}\text { Concern regarding loss of } \\
\text { competence }\end{array}$ & (37) \\
\hline & & Lack of medical skills practice & (37) \\
\hline & Work environment & $\begin{array}{l}\text { Lonelines and isolation working } \\
\text { from home }\end{array}$ & $(37)$ \\
\hline & $\begin{array}{l}\text { Workload and } \\
\text { workflow }\end{array}$ & Requires higher concentration & $(45,46,58)$ \\
\hline & & More tiring & $(45,46,50,58,60)$ \\
\hline & & Difficulties structuring time & $(37,45)$ \\
\hline & & More stressful & $(54)$ \\
\hline & & $\begin{array}{l}\text { Administration or preparation takes } \\
\text { time }\end{array}$ & $(36,50)$ \\
\hline & & Lack of administrative support & $(35,36,41)$ \\
\hline & Dissatisfaction & $\begin{array}{l}\text { Overall dissatisfaction with digital } \\
\text { care visits }\end{array}$ & $(61)$ \\
\hline & & $\begin{array}{l}\text { Felt that patients' needs were not } \\
\text { adequatly addressed }\end{array}$ & $(56,61)$ \\
\hline & & $\begin{array}{l}\text { Digital care visits are inferior to in- } \\
\text { person visits }\end{array}$ & $(35,46,54,59,61)$ \\
\hline & $\begin{array}{l}\text { Patient-professional } \\
\text { relationship }\end{array}$ & Difficulty fostering rapport & $(44,60)$ \\
\hline & & $\begin{array}{l}\text { Difficulty in dealing with emotional } \\
\text { situations }\end{array}$ & $(46,50,59,60)$ \\
\hline & & Digital care visits are less personal & $(56,59)$ \\
\hline & & Digital care visits were less intimate & (58) \\
\hline & & $\begin{array}{l}\text { Difficulty to maintain patient's } \\
\text { attention/engagement }\end{array}$ & $(46,47,58,60)$ \\
\hline & $\begin{array}{l}\text { Unmet patients' } \\
\text { expectations }\end{array}$ & $\begin{array}{l}\text { Patient's desire for physical } \\
\text { consultation was unmet }\end{array}$ & $(56,57)$ \\
\hline
\end{tabular}




\begin{tabular}{|c|c|c|c|}
\hline \multirow[t]{10}{*}{ Theme } & Category & Subcategory & Reference \\
\hline & & $\begin{array}{l}\text { Unrealistic patient expectations and } \\
\text { poor understanding }\end{array}$ & (13) \\
\hline & & $\begin{array}{l}\text { Patients are reluctant to pay for } \\
\text { digital care visits }\end{array}$ & (57) \\
\hline & Technical challenges & Patients lack technical skills & $(46,57)$ \\
\hline & & $\begin{array}{l}\text { Patients lack comfort to use } \\
\text { technology }\end{array}$ & $(46,50,57,58)$ \\
\hline & & $\begin{array}{l}\text { Restricted access to technology due } \\
\text { to socioeconomic status }\end{array}$ & (57) \\
\hline & $\begin{array}{l}\text { Complications from } \\
\text { the patient's side }\end{array}$ & $\begin{array}{l}\text { More visit cancellations or } \\
\text { rescheduling by patients }\end{array}$ & $(51,58)$ \\
\hline & & Disruptions from patients side & $(46,58)$ \\
\hline & $\begin{array}{l}\text { Patient safety and } \\
\text { privacy }\end{array}$ & Safety concerns & $(37,38,46)$ \\
\hline & & Privacy concerns & $(46,59,60)$ \\
\hline \multirow[t]{13}{*}{ Barriers } & Physical barriers & $\begin{array}{l}\text { Inability to apply certain treatment } \\
\text { techniques }\end{array}$ & $(36,43,45)$ \\
\hline & & $\begin{array}{l}\text { Innability to provide written } \\
\text { information }\end{array}$ & (57) \\
\hline & & $\begin{array}{l}\text { Lack of physical examination is } \\
\text { problematic }\end{array}$ & $\begin{array}{l}(36,38,39,43,44,47,49,51- \\
55,57)\end{array}$ \\
\hline & & $\begin{array}{l}\text { Inability to see non-verbal cues } \\
\text { clearly }\end{array}$ & $(46,49,50,54,58,59)$ \\
\hline & Suitability & $\begin{array}{l}\text { Inapplicable for some types of } \\
\text { patients }\end{array}$ & $(35,38,45,47,54)$ \\
\hline & & $\begin{array}{l}\text { Inappropriate for sensitive } \\
\text { conversations }\end{array}$ & (57) \\
\hline & Technical issues & Connectivity issues & $(36,42,46,47,52,54,56,59,61)$ \\
\hline & & $\begin{array}{l}\text { Poor quality or lost audio and/or } \\
\text { video }\end{array}$ & $(42,47,52,55,56,59,61)$ \\
\hline & & $\begin{array}{l}\text { Lack of technical support when } \\
\text { working off ofice hours }\end{array}$ & (37) \\
\hline & & $\begin{array}{l}\text { Lack of unified documantation } \\
\text { system }\end{array}$ & (37) \\
\hline & & Difficult or uncomfortable to use & (35) \\
\hline & $\begin{array}{l}\text { Reimbursement } \\
\text { issues }\end{array}$ & $\begin{array}{l}\text { Ambiguity of insurance coverage } \\
\text { status }\end{array}$ & (57) \\
\hline & & $\begin{array}{l}\text { Training and administration time } \\
\text { are not compensated }\end{array}$ & (36) \\
\hline
\end{tabular}




\begin{tabular}{|c|c|c|c|}
\hline Theme & Category & Subcategory & Reference \\
\hline & & $\begin{array}{l}\text { Reimbursement model needs to be } \\
\text { adapted }\end{array}$ & $(13,41,44)$ \\
\hline
\end{tabular}

Table 5

Suggestions for improvement

\begin{tabular}{|c|c|c|c|}
\hline Theme & Category & Subcategory & Reference \\
\hline \multirow[t]{11}{*}{$\begin{array}{l}\text { Suggestions for } \\
\text { improvement }\end{array}$} & $\begin{array}{l}\text { Training and } \\
\text { education }\end{array}$ & Provide proper training in using the technology & $(13,36,42,44,48,60)$ \\
\hline & & $\begin{array}{l}\text { Tutorial materials on how to use the technology } \\
\text { for professionals and/or patients }\end{array}$ & $(51,53)$ \\
\hline & & Promotion and education on digital care visits & $(41,44)$ \\
\hline & $\begin{array}{l}\text { System and } \\
\text { tools }\end{array}$ & Standardized equipment for providers & $(48)$ \\
\hline & & $\begin{array}{l}\text { Incorporate videoconferencing tools into EHR } \\
\text { system }\end{array}$ & (37) \\
\hline & & Implement triage system & $(13,37,54)$ \\
\hline & & Enhanced data security & $(42)$ \\
\hline & & Use double web-cameras & $(50)$ \\
\hline & $\begin{array}{l}\text { Clinician } \\
\text { support }\end{array}$ & $\begin{array}{l}\text { Promotion of self-care for healthcare } \\
\text { professionals }\end{array}$ & $(47)$ \\
\hline & & Incorporate administration/coordination support & $(42,44,48)$ \\
\hline & & $\begin{array}{l}\text { Ensure access to suitable work environment and } \\
\text { tools }\end{array}$ & $(46)$ \\
\hline
\end{tabular}

\subsection{Positive experiences/benefits of digital care visits}

Numerous benefits and aspects of possitive experience have been reported in the reviewed literature. Aspects such as benefits of remote work, efficiency, satisfaction with digital care visits and benefits for the patient were identified. (Table 3)

\section{Benefits of remote work}

The advantages of flexibility with working hours and workplace have been reported in literature repeatedly. Cioffi's study has found that nearly $60 \%$ of psychotherapists reported greater flexibility, (45) in Koch and Guhres's research physicians expressed that digital care visits allow "flexibility to work from home" and "flexibility regarding working time." (13) Hardy et al in their mixed-methods study found that therapists providing teletherapy for couples felt similarly "Flexibility in scheduling and location." (46) Björndell \& Premberg have found that "the flexibility of work and the regulated assignment online were positive for the physicians' work situation and well-being." (39) Sugarman et al have also discovered that therapists identify "scheduling/flexibility" as an advantage. (47) The same findings mentioned in Fernemark's et al study - flexibility with work hours and the ability to choose where to work from were considered advantages by general practitioners in Sweden. (37) 
Saved travel time and costs were also mentioned as benefits in several publications. Physicians from three studies thought the use of digital care visits saves the commuting time, $(39,41,47)$ this plays a role in enhancing healthcare professionals' quality of life: "saving travel time, being present at home, and participating in family activities [...] was considered beneficial." (39)

Digital care visits provide flexibility which contributes to healthcare professionals feeling less stressed and more at ease. A small percentage of psychotherapists in an Italian study agreed that they felt more relaxed during online sessions. (45) Björndell \& Premberg wrote that "working from home was appreciated by the physicians because it let them work in peace, feel less stressed, and enjoy being at home." (39) Additionally, the same study showed that feeling less stressed is a consequence of reduced workload which was also indicated as a positive experience. Similar results have been shown in Fernemark's et al study. (37)

Working remotely minimized social contacts and reduced the risk of spreading or getting infected with communicable diseases. This aspect was raised in a couple of studies - Sugarman et al reported that digital care visit "supports personal safety concerns, including COVID-19 risk" (47) and in Björndell \& Premberg's paper "reduced risk of infection transmission." (39)

\section{Efficiency}

It was indicated in several studies that working with digital care visits is more efficient in the sense that it saves time and increases productivity. Kemp's et al, (48) Koch \& Guhres's (13) as well as Saiyed's et al (49) studies have shown that digital visits took less time than in person visits according to healthcare professionals. Eight out of twenty-eight selected studies indicated that digital care visits increase productivity or efficiency. Healthcare professionals felt that by using telemedicine, they could be more productive, $(41,45)$ more structured and efficient due to greater focus during the sessions, (50) the use of technology made the visits more efficient, (35) meaning that the patients were already prepared, physicians could easily end the video calls and consult another patient right away. $(48,51)$ Some physicians reported that it was easier to consult patients via digital care visits because

their cases were simpler than those in physical visits, which in turn allowed to treat them more quickly, efficiently as well as consult more patients. $(37,39)$

\section{Satisfaction}

Overall, healthcare professionals, regardless of their specialization or location, had mostly positive experience with digital care visits ranging from at least slightly $(46)$ to highly satisfied $(35,40,44)$ as stated in nearly half of the selected publications. Professionals felt that digital care visits have a positive influence on their work environment, (13) were generally happy with their experience, $(41,43,51-53)$ and enjoyed it. (49)

The usability of digital visits varied due to the use of different platforms. Some studies state that systems for digital care visits were easy to learn how to use $(41,44)$ and twelve out of twenty-eight studies found that they were quite straight forward and easy to use. $(13,39,41,43,47,49,51,53-56)$ Several publications revealed that healthcare professionals were satisfied with the system/platform itself $(13,48,52)$ and/or appreciated its features. (47)

Another important aspect of a visit is the interaction between the healthcare professional and the patient. In six out of twenty-eight selected studies healthcare professionals expressed having a positive experience regarding patient- 
professional interaction. Clinicians were able to discuss patients' issues, assess their condition and offer treatment advice effectively and in many cases an in-person visit was unnecessary. $(39,43,49,52,53)$

\section{Convenient, accessible care and saved resources for patients}

Digital care visits offer significant benefits for clinicians as well as patients and their families. Increased flexibility and greater accessibility are namely the most emphasized perks of digital care visits. Digital care visits allow patients schedule visits at their convenience, $(13,13,39,47,51,52)$ patients who have other responsibilities such as caring for children - do not need to organize childcare for when they are away. $(47,57-59)$ Digital care visits offer high quality medical care for patients from rural or remote areas where such care is inaccessible, $(13,39,41$, $52,59)$ patients who are homebound due to their medical conditions or those who simply do not have the means or wish to travel to a health care facility. $(47,51,57,58)$ Saving travel costs was mentioned multiple times in eight reviewed articles. $(13,47,51,52,57-59)$ Patients feels more at ease when they are surrounded by the environment they are used to and family and their loved pets. $(39,46,51,52)$ This feature was emphasized in mental health related studies. Patients tended to be more open, felt more secure and often shared more with their therapists during the online sessions from their homes. $(46,47,50)$ Having remote visits from patient's home allows for better family member inclusion, (57) their education on the patient's condition and how to care for them. (57) Hinman's et al study on remote physiotherapy found that patients felt empowered when doing exercises at home, digital care visits increased their adherence to the program and allowed them to learn correct and safe exercise techniques as reported by consulting physical therapists. (51) Patients gain more confidence in performing rehabilitation exercises at home (51) and take up more initiative to care for themselves and try to be more self-reliant, (56) as well as form stronger therapeutic alliance or cooperation with therapists. $(46,47)$

Furthermore, by having health care visits remotely, patients avoid transmission of and exposure to communicable diseases which enhances their personal safety and contributes to controlling the spread of infectious diseases. (39, 57) Overall, clinicians from several studies indicated that they felt their patients were satisfied with digital care visits, their complaints were addressed, and they got the care necessary. $(37,38,49,60)$

\subsection{Facilitators}

\section{New perspectives in remote care}

Digital care visits employ videoconferencing technology, and this opens new perspectives in remote care. The ability to get instant non-verbal feedback through video i.e., see the patients' facial reactions, their body language enables healthcare professionals to get more unspoken information from the visit. (51) Being able to see patient's symptoms during the video consultation, allows health care professional to intervene in real time. (58) Some clinicians thought that caring for patients remotely made them focus more on what was the most important in the treatment. $(50,51)$

Clinicians noted that digital care visits felt more personal in Hinman's study, because physical therapists had to really listen to their patients to provide a good service. (51) Levy et al stated that in a therapeutic setting with a close-up video of the patient's face the session can be as intimate as in-person. (59) Being able to see the patient was one of the reasons for healthcare professionals' preference to digital care visits over phone consultations. (13, 56) Interestingly, another new perspective brought by digital care visits which was not present in traditional visits is a possibility to get insight into patient's home environment. This allows clinicians to get a better overview of the patient's quality of life, gives valuable insight of how they communicate with their relatives or pets if they are in the 
picture - it creates a unique possibility to "be closer" to the patient and many healthcare professionals appreciated that. $(35,39,46,47,58)$ According to clinicians, digital care visits allow for shorter and more frequent visits $(47,50$, $57)$ and ensure continuity of care $(46,47)$ supporting access to care for patients.

\section{Technical qualities}

Eight out of twenty-eight studies indicated that technical features such as audio and video were of good quality or there were no issues with them during the visits. $(13,37,38,43,49,51,53,55)$ Clinicians thought they could hear and see patients well enough to provide healthcare services.

\section{Possibilities of digital care visits}

With the use of videoconferencing technology for digital care visits it is possible to consult, examine and diagnose patients as stated in eight of twenty-eight reviewed studies. $(35,39,43,46,49,52,55,58)$ Digital care visits seemed like a suitable form of care for some clinicians, (52) $57 \%$ of therapists on Becevic's et al study reported they could treat patients via digital care visits, (55) $83 \%$ of couple therapists in Hardy's et al study replied they could at least somewhat solve conflicts as effectively as in-person, (46) in Kirby's et al survey surgeons were fairly confident in their diagnoses and assessments, (43) other studies showed that clinicians were comfortable to treat their patients or their patients were appropriate for treating via telemedicine. $(35,39,49)$ Several studies indicated that clinicians felt they could establish connection with patients which is an imperative part of patient-clinician interaction. (46, 47) Some even stated that the relationship with patients was as authentic as face-to-face. $(49,60)$

\section{Suitability}

Four of the selected studies explained that digital care visits are best suitable for follow-up visits, as it is easier to consult a patient who is known and whose condition is not completely new for the healthcare professional. $(38,40$, 44,53 ) Some other studies showed that in clinicians' opinion digital care visits are suitable to treat mental health problems because no physical examination is required, $(38,39)$ some less complicated skin conditions if the video quality is good enough, $(39,47)$ for palliative and pediatric care, $(35)$ for chronic disease management, $(40)$ GPs thought digital care visits work great for administrative purposes such as extending a sick leave for working patients. (38)

\subsection{Negative experiences/challenges of using digital care visits}

Despite numerous advantages of digital care visits, there are multiple drawbacks and challenges reported in the literature. Clinicians have encountered issues with decision making, workload and workflow problems, patientprofessional relationship related considerations, patient related challenges or low satisfaction. These negative experiences and challenges will be presented further on.

\section{Complicated decision making}

Seven studies out of twenty-eight declared that clinicians experience difficulties while making decisions regarding patient's diagnosis, treatment or referrals. $(13,37-39,47,53,54)$ In Koch \& Guhres's paper physicians reported that "information for decision making is limited" in digital care visits. (13) Johnsen's et al study revealed that $15 \%$ of GPs were worried that they have possibly missed signs of serious disease, also more than a half of physicians considered the inability to perform a physical examination as a serious disadvantage. (38) In other publication it was explained that physicians think digital care visits will never be able to replace hands-on examination. (53) 
Sugarman et al articulated that according to therapists' experience, it was complicated to treat easily distracted patients, to visualize their psychomotor symptoms, measure vital signs and prescribe medication based on their observations and patients' complaints discussed during digital care visit. (47) Other authors got similar findings regarding these difficulties. $(37,39,51,57,59)$ Physicians and therapists also saw disadvantages in having to rely on the patients' observations and descriptions to diagnose, assess or prescribe proper treatment, $(35,39,51,57,59)$ GPs were hesitant at times if they should trust patient's complaints without an examination when extending their sick leaves or prescribing medication. (39)

Several studies revealed that healthcare professionals had difficulties guiding the right patients to digital care visits. It was complicated for physicians to sort the patients whose conditions were appropriate to be treated via digital care visits, who needed to have an in-person visit, and who could have their problems solved by other health professionals e.g., by nurses to utilize the limited healthcare resources efficiently. $(13,37,39)$

\section{Professional development and work environment}

Clinicians' concerns such as lack of medical skills practice and loss of competence were raised in Fernemark's et al paper. (37) GPs worried that digital care visits often deal with simpler cases where physical examinations and more complicated medical manipulations are unnecessary, and they were concerned that by working exclusively with digital care visits they would lose some of their skills and competence. (37)

\section{Workload and workflow}

Clinicians in several studies reported that digital care visits require higher level of concentration compared to traditional visits. $(45,46,58)$ Over $55 \%$ of therapists experienced that digital care visits require higher level of concentration in Cioffi's et al study; (45) therapists from another study pointed out that $30 \%$ of them experienced less engagement, had to work harder because they needed to look over the technical aspects of the session, tend to non-verbal communication which was difficult for $80 \%$ of the therapists, and address disruptions during the visits which occurred for $92 \%$ of the respondents. (58) Therapists in Hardy's et al study experienced "clinician fatigue lethargy, tiredness, and discomfort" as well as claimed digital care visits were more tiring. (46) Similarly, other studies reported that treating patients online is more tiring because the clinician needs to compensate for the absence of physical presence, focus harder and use other senses than touch to assess patients, often help patients with technology issues and deal with sometimes higher workload. $(45,46,50,58,60)$ Healthcare professionals from Cioffi's et al and Fernemark's et al studies felt it was more difficult to structure their time when working from home and they were unsure when and if they should take breaks as they would while working from the office. (37, 45)

Around one-fifth of the physicians who participated in Gold's et al survey replied that they experience increased stress while working with digital care visits. (54) Some identified that digital care visit type of care even conflicted with their views on how care should be delivered. (54) Johnsson et al and Paulik et al discovered that clinicians feel that administration and preparation for digital care visits takes a lot of time, because they must adapt certain treatment techniques to a new setting. $(36,50)$ Other authors found that clinicians experience a lack of administrative support and they needed to schedule visits as well as do other tasks that a secretary or a nurse could take over instead of focusing on treating patients. $(35,36,41)$

\section{Dissatisfaction}

Page 18/32 
One study from the USA has reported that $58 \%$ of the participated physicians were generally neutral or not satisfied with digital care visits and almost a half of them were concerned that healthcare professional-patient relationship was compromised as a result of digital care visits. (61)

Two other studies discovered that clinicians felt that their patients' needs were not adequately addressed as some patients could not get the care they needed online, or they wished for physical presence and social interaction with the clinician. $(56,61)$ Overall, five studies reported that healthcare professionals consider digital care visits inferior to face-to-face visits and preferred traditional visits over digital ones. $(36,46,54,59,61)$

\section{Patient-professional relationship}

Several studies addressed the issue of healthcare professionals having difficulty fostering rapport with their patients. $(44,60)$ Bekes et al and Tenforde et al studies reported that healthcare professionals felt they had difficulties connecting emotionally to the patient, it was harder to grasp their emotions. $(44,60)$ Mental health professionals expressed it was difficult to deal with emotional situations in digital care visits. $(46,50,59,60)$ Mainly due to being unable to properly see patients' body language and facial expressions and inability to use certain conflict management techniques from a distance. $(46,50,59,60)$

Another concern regarding patient-professional relationship was digital care visits being less personal than face-toface visits. This concern was reported in two studies that explained this happening due to lack of physical presence and being there for the patient. $(56,59)$ Similarly, therapists from Wade's et al study felt that therapy sessions via digital care visits were less intimate. (58) Additionally, mental health workers experienced it was difficult to maintain patients' attention and engagement due to their condition or distractions at home. $(46,47,58,60)$

\section{Unmet patients' expectations}

A couple of studies reported that healthcare professionals felt their patients' desire for physical consultation was unmet, especially with oncological and geriatric patients. $(56,57)$ At times, according to clinicians, patients desired to be examined physically to feel more sure and secure regarding their diagnosis (57) or simply social interaction was important for homebound patients. (56) Koch \& Guhres's study found that physicians reported patients having unrealistic expectations or poor understanding of what could be done during digital care visits resulting in dissatisfaction. (13)

\section{Technical challenges}

The fact that patients have different socioeconomic status was related to their access to technology such as smartphones, tablets and computers (57) meant not all patients got access to digital care visits as well as patients' lack of technological skills $(46,57)$ or patients' lack of comfort to use technology $(46,50,57,58)$ often prevented successful interaction via digital care visits.

\section{Complications from the patients' side}

Other challenges that clinicians had to deal with were more visit cancellations or rescheduling by patients as the result of increased flexibility as reported by Hinman et al and Wade et al. $(51,58)$ Disruptions when patients get distracted by their family members or daily chores also have a negative effect on the overall experience. $(46,58)$ Moreover, Heyer et al stated in their study that sometimes patients do not feel they should pay for a digital care visits the same as they do for a traditional one. (57)

Page 19/32 


\section{Safety and privacy}

Several studies have covered clinicians concerns regarding patient safety, privacy, confidentiality, and informed consent. Patient's immediate safety due to acute conditions and the need of emergency hospitalization $(37,38)$ or safety regarding conflicts at home and risks posed by their mental state (46) were of concern for clinicians. Privacy was an issue discussed in three studies - in therapy sessions privacy is important and it is severely compromised when a patient is unable to find a place in their homes where they feel secure and cannot be overheard by the family members. $(46,59,60)$

\subsection{Barriers}

\section{Physical barriers}

Using digital care visits for treatment sometimes poses barriers such as inability to apply certain treatment techniques that could otherwise be used in a face-to-face visit. Cioffi's et al study showed that $50.69 \%$ of responded therapists felt digital care visits restrict or prevent from applying certain techniques (45) and surgeons from Kirby's et al study had similar experience. (43) Allied health specialists reported that the medical interventions were limited to those that did not require a trained occupational therapist's presence and therefore patients were less successful in reaching motor goals. (36)

Similar problem occurred to healthcare professionals trying to examine the patients. In 13/28 studies, clinicians reported lack of physical examination was problematic. $(36,38,39,43,44,47,49,51-55,57)$ Surgeons from Kirby's et al study pointed out, they had difficulty measuring sensation and tenderness, (43) occupational therapists sometimes struggled evaluating motor skills, (36) Mammen et al found occasional technical problems as well as inability to touch sometimes hindered with physicians ability to conduct examination, (52) physical therapists experienced discomfort without hands-on assessment, (51) other studies showed that clinicians thought not having a physical examination is a loss and digital care visits cannot replace hands-on examination. $(38,39,44,47,49$, $53-55,57)$ Mental health workers $(46,50,58,59)$ and physicians $(49,54)$ considered inability to clearly see nonverbal cues a disadvantage.

\section{Suitability}

Clinicians expressed that digital care visits were not always a suitable from of care for some patients. Studies have found that digital care visits were less applicable for new patients, $(38,54)$ patients that have musculoskeletal, skin, $(38,54)$ pediatric problems, acute and severe health issues $(38,57)$ or conditions that certainly required physical examination; (35) they were also unsuitable for patients with severe mental problems such as paranoia, psychosis etc. (47) Medical oncology professionals noted that digital care visits were inappropriate for sensitive conversations with the patient such as for delivering bad news. (57)

\section{Technical issues}

Technical issues may become a serious barrier in providing quality care. In ten out of twenty-eight studies, authors reported that healthcare professionals have encountered connectivity issues. Lost connection, $(36,46,56,57,59)$ difficulty to log on, (47) patients not being able to connect, $(42)$ poor or unstable internet connection, $(54,56)$ over a half of the clinicians in Mammen's et al and Yu's et al studies indicated they experienced audio, video and connectivity issues. $(52,61)$ Healthcare professionals from other studies also expressed they had problems with 
poor quality sound or video during the visits and affected the overall quality of the consultation as it was more difficult to communicate and assess the patient. $(42,47,55,56,59)$

\section{Reimbursement issues}

Healthcare professionals mentioned problems related to pay for their work with digital care visits. Due to rapid telehealth adoption the insurance companies have not adapted their policies on the coverage regarding digital care visits which in turn is problematic to healthcare professionals. (57) Allied health therapists experienced that they had to spend a lot of time for training to use digital care visits and administrate them, while they were only compensated for the factual duration of the visits, not the preparation - this posed risk for job dissatisfaction. (36) Other authors suggested, the reimbursement models should be adapted to offer a fair pay for healthcare professionals providing care via this technology. $(13,41,44)$

\subsection{Suggestions for improvement}

Lastly, a theme about possible suggestions for improvement of digital visits emerged from the reviewed literature. The findings suggest that main improvements could be done in training and education, improving tools and adapting system as well as offering greater support for clinicians.

\section{Training and education}

Providing proper training for healthcare professionals on how to use the technology and train them in providing health care services remotely would be beneficial and improve clinicians' experience as well as increase their confidence with the use of digital care visits as reported in six studies. $(13,36,42,44,48,60)$ Preparing tutorial materials such as video clips or booklets on how to use the digital care visit platform to support both professionals and patients was indicated as a potential benefit. $(51,53)$ Promotion and education about digital care visits could raise awareness, encourage and support healthcare professionals to use the technology, $(41,44)$

\section{System and tools}

Standardized equipment for providers would ensure that digital care visit platforms are supported by all used devices, and it would be easier to use as stated in Kemp's et al study. (48) Clinicians would also benefit from videoconferencing tool being integrated into the EHR system that they use routinely to grant easy access to the patients' records. (37) Additionally, healthcare professionals find it difficult to guide the right patients to the digital care, therefore an implementation of a triage system would be helpful. $(13,37,54)$ As a response to safety and confidentiality concerns, improvements could be made to enhance security by setting passwords for the sessions, end-to-end encryption and ensuring GDPR compliance. (42) Paulik's et al study suggests using two cameras for the patients - one set up to show a close-up image of the face and another to capture the whole body in order to improve visibility and understanding of non-verbal cues shared by the patient during therapy sessions. (50)

\section{Clinician support}

Providing clinicians with properly functioning devices and ensuring they have a suitable work environment that is private, quiet, and well-lit would contribute to the professional's comfort and the quality of the consultation. (46) Not putting a burden of excessive administration and coordination tasks that could be done by other staff on the clinicians $(42,44,48)$ could help them cope with the workload better. Lastly, another important aspect is promotion 
of self-care. It has been reported that digital care visits may be more tiring than the regular sessions, thus ensuring that professionals care for themselves to cope with fatigue caused by digital care visits is crucial. (47)

\section{Discussion}

The aim of this study was to explore the literature and find out about user experience of using digital care visits from different healthcare professionals' point of view. (62) The results of this study showed that healthcare professionals mostly had positive experiences with digital care visits. Many of the authors stated, healthcare professionals thought digital care visits are advantageous for the professionals regarding benefits of remote work, efficiency, satisfaction with this type of consultation, and new perspectives in remote care. Clinicians particularly appreciated the ability to be flexible in terms of work hours and choosing the workplace, the increased productivity and efficiency, as well as the ease of use of the technology. Similarly, when exploring patients' point of view a systematic review has shown comparable findings - the patients had overall high satisfaction as well as were satisfied with the system experience, information sharing and consumer focus. (6)

Many healthcare professionals agreed that digital care visits significantly increased the accessibility of health care services to patients who live in remote locations, are not able to travel to a health facility due to various reasons (limited or restricted mobility, social phobias, lack of resources etc.) or even those with responsibilities at home such as caring for their young children or sick relatives. These findings are in line with other studies that explored the caregivers' and patients' point of view towards remote care. $(63,64)$ A significant portion of studies declared clinicians found their patients became more confident in themselves, felt more at ease and cooperated in their treatment better when they had the chance to stay in their home environment. Specifically, this was mentioned not only by mental health professionals, who rarely need to apply hands-on techniques in their treatment but also physical therapists who were teaching their patients exercise techniques and managed to achieve good outcomes. Facilitators found in the literature were related to new perspectives and features of remote care such as real-time video aspect that added visual information compared to consultations over the phone. Health care professionals had mixed experiences with the technical quality. Nine of the selected papers reported the quality being good or no issues at all, while in ten of the other studies it was reported that clinicians experienced technical issues related to video/audio quality or connectivity issues from their or the patients' side.

The possibilities of digital care visits were rated positively among healthcare professionals. Physicians and therapists thought it was possible to consult, examine, diagnose, and treat patients via digital care visits. However, in almost half of the reviewed papers, healthcare professionals expressed that the lack of physical examination was at least somewhat problematic. Particularly, general practitioners and healthcare professionals, who work with musculoskeletal disorders and oncologic patients found the inability to physically examine patients to be an obstacle in at least some cases. Overall, there were mixed opinions on whether digital care visits could replace faceto-face visits. Health care professionals reported that digital care visits are suitable to assess some conditions, such as simpler skin conditions, mental health issues, and other conditions that did not require touch to assess as well as follow up visits; on the other hand, when the conditions were more complicated or the patient was new, clinicians reported that a physical visit would be more suitable. Compared with another study, health personnel found both benefits and disadvantages of treating patients remotely - some found it advantageous because the patients did not need to wait long to receive care, other expressed it was easier for them to simply write a referral rather than have a digital care visit. (64) 
The findings suggest that digital care visits are suitable for visits that involve treatment of rather simple conditions, those that do not require physical examination or do not involve sensitive conversations that would be better handled in face-to-face visits. Naturally, selecting the right kind of patients for remote care, would decrease the complexity of decision making when a professional must rely on other senses and information collected without being physically present with a patient. This could be achieved by employing a triage system as suggested in two Swedish studies $(13,37)$ and one American study. $(54)$ By implementing a triage system that would filter the patients and direct them to the right type of care, limited medical resources could be utilized more efficiently. Other suggestions for improvement include training and educational materials - this could potentially improve healthcare professionals experience with using digital care visits, as well as raise awareness among those who have not started to use it yet and encourage to employ the technology. Conversely, general practitioners from another study noted that even though reading manuals on how to use the technology were often helpful they rarely found the time "to read and understand the instructions" due to tight scheduling. (64)

Some healthcare professionals expressed digital care visits were not well integrated into their workflow, they felt unsure when prescribing medication to patients without knowing their health history. (39) Using separate videoconferencing tools, scheduling consultations, and coordinating remote care added up to the workload, (54) thus implementing the necessary tools into the EHR system could make the workflow smoother and would allow healthcare professionals access patients' health records, ensuring greater confidence for the clinicians and safety for the patient. Another important aspect of remote consultations or remote work in general is fatigue that comes from communicating online and the feeling of isolation and loneliness from not being able to meet with peers. One study suggested self-care should be promoted among healthcare professionals working remotely. (47) Online social activities for the healthcare teams such as communication channels, virtual social groups, peer support and games or team challenges could be offered to healthcare professionals to provide them with opportunity for casual and less formal communication with colleagues as a replacement of running into each other at the office. (65) This in turn could make them feel more connected to the team and less isolated.

Few of the studies in this review involved resident doctors or young professionals who do not have extensive work experience. $(54,57,61)$ It was reported that they had more difficulties in using digital care visits, it was more complicated to assess and diagnose patients due to limited work experience $(54,57,61)$ and therefore it is possible that their experience with remote consultations was more negative. It is possible, that clinicians with more in-person work experience would be a better fit for providing such services (39) and they would be more comfortable in such setting. Alternatively, it could be beneficial if young professionals got mentorship or support from their more experienced peers whenever they needed in order to increase their confidence. Also, as mentioned in some of the reviewed articles, training, and education on how to use the technology and provide remote health care would be beneficial. (66)

It is worth mentioning that as a result of COVID-19 pandemic, the adoption of digital care visits was extremely rapid and many of the health organizations were unprepared for it. Health workers were pushed out of their comfort zones and forced to move to remote care abruptly without having the time to prepare or train for it properly, many of the organizational changes had to be made suddenly to make the shift happen. (45-47) Therefore, the studies published during the pandemic were strongly influenced by these aspects and healthcare professionals' experiences of using digital care visits were affected by the sudden shift as well as general stress and pressure caused by this unprecedented contagion. Many of the professionals have not used digital care visits prior the pandemic and the sudden change may have influenced their experiences more negatively. However, on the contrary, 
many stated an overall positive experience and would continue to use the technology to smaller or larger extent in the post-pandemic future. $(35,38,41,44,46)$

\section{Implications of this study}

It is clear from the results - digital care visits will never fully replace in-person visits which was correspondingly mentioned in other literature, $(67,68)$ however, it is possible to provide health care services via digital care visits in cases that do not require physical examination for the assessment or any medical procedures for the treatment. Moreover, digital care visits should not take over all the in-person visits but act as a complement to the physical visits - it is important to note that the social interaction and physical presence facilitates better conditions for showing empathy and simply "being there" for the patient, which are essential parts of care and bear significant value to patients and professionals alike.

Admittedly, only a fraction of healthcare professionals' specializations was included in the reviewed studies. The knowledge on experience of surgeons', midwives', dental care professionals' and other specialized physicians' other than those included in this study is limited and should be studied in the future to get a clearer picture of their perspectives. The COVID-19 pandemic is surely transforming the remote care and there have already been studies that described the shift towards digital care visits and the organizational changes. $(11,18,69,70)$ However, a more detailed review of how the perspectives have changed and how the rapid adoption has affected the use and experience of clinicians could be beneficial in the future. In addition, more research could be done on the usability of digital care visits integrated to the EHR systems because so far, the clinicians mostly use separate platforms. Finally, more explorations of how digital care visits could be combined with in-person care and the perspectives of professionals, patients and caregivers on this approach could be studied further.

\section{Strengths and limitations}

One of the strengths of this study is a comprehensive search strategy in three large databases that contain big amounts of healthcare and technology related publications. The search was carefully documented. The search queries were tested and adjusted to achieve the retrieval of more relevant results. MeSH terms were used in the search to broaden the search. Many studies were retrieved from the databases and additional search for the grey literature was performed. Various types of publications and different study types were included in the review to ensure broad coverage on the topic. All the citations were managed using a reference system Mendeley to ensure orderly documentation.

This scoping review is not without limitations. Firstly, by filtering the search results by the language (only including English papers) may have prevented from getting more results and potentially missing some data that could have been included in this study. Secondly, a limited time frame may have affected the quality and quantity of the findings. Additionally, lack of critical appraisal is one of the disadvantages of the scoping review type of studies and therefore poses a risk of bias. (71) The search terms and search queries were discussed in detail, the search queries were adjusted, and new search words were added several times. However, the screening and the selection of studies were performed by the first author which also increases a risk that some studies were missed. (72)

\section{Conclusion}

To summarize, this scoping review explored the existing literature on user experience of using digital care visits from different healthcare professionals' point of view. The themes of positive experiences/benefits, facilitators, 
negative experiences/challenges, barriers and suggestions for improvement were identified. The findings suggest that overall, healthcare professionals had a positive experience with the use of digital care visits and saw numerous benefits of this type of remote care for themselves as healthcare workers as well as for their patients. Despite the overall positive experience, clinicians reported challenges and issues they faced when using the technology including difficulties in decision making, physical barriers, technical issues, suitability concerns and others. Finally, it is suggested that digital care visits are not able to replace in-person visits in full, however they could be effectively used in combination for treatment and management of suitable conditions. Further research could be done to explore experiences of other healthcare professionals not represented in this study, as well as the effects of the COVID-19 pandemic of digital care visits use.

\section{Abbreviations}

COVID-19 - Coronavirus disease

EHR - Electronic Health records

GDPR - General Data Protection Regulation

GPs - General practitioners

ICT - Information and Communications Technology

MeSH - Medical Subject Headings

PRISMA - Preferred Reporting Items for Systematic reviews and Meta-Analyses

PRISMA-ScR - PRISMA Extension for Scoping Reviews

\section{Declarations}

\section{Ethics approval and consent to participate}

Not applicable.

\section{Consent for publication}

Not applicable.

\section{Availability of data and materials}

The datasets used and/or analysed during the current study are available from the corresponding author on reasonable request.

\section{Competing interests}

The authors declare that they have no competing interests.

\section{Funding}


The project was supported by Health Informatics Center at Karolinska Institute. The design of the study, data collection, analysis and writing the manuscript was not affected by the funding.

\section{Authors' contributions}

I.L. and N.D. designed the study. I.L and N.D designed and discussed the search queries. I.L undertook the data collection and screened all potentially relevant studies. I.L performed the initial data analysis independently and discussed the categories and sub-categories with N.D. I.L. prepared a first draft of the manuscript and N.D. contributed to the writing of the manuscript. Both authors have read and agreed with the last version of the manuscript.

\section{Acknowledgements}

Not applicable.

\section{References}

1. World Health Organization. Telemedicine: opportunities and developments in Member States: report on the second gloal survey on eHealth. Geneva; 2010 p. 8-11.

2. Videoconferencing - MeSH - NCBI [Internet]. [cited 2021 Mar 11]. Available from:

https://www.ncbi.nlm.nih.gov/mesh/?term=videoconferencing

3. Granström E, Wannheden C, Brommels M, Hvitfeldt H, Nyström ME. Digital tools as promoters for personcentered care practices in chronic care? Healthcare professionals' experiences from rheumatology care. BMC Health Serv Res. 2020 Dec;20(1):1108-1108.

4. Demi S, Hilmy S, Keller C. Doctor at Your Fingertips: An Exploration of Digital Visits from Stakeholders' Perspectives. Life. 2020 Dec;11(1):6-6.

5. MacDonald GG, Townsend AF, Adam P, Li LC, Kerr S, McDonald M, et al. eHealth technologies, multimorbidity, and the office visit: Qualitative interview study on the perspectives of physicians and nurses. J Med Internet Res. 2018 Jan;20(1):e8983-e8983.

6. Orlando JF, Beard M, Kumar S. Systematic review of patient and caregivers' satisfaction with telehealth videoconferencing as a mode of service delivery in managing patients' health. Borsci S, editor. PLOS ONE. 2019 Aug;14(8):e0221848-e0221848.

7. Melian C, Kieser D, Frampton C, C Wyatt M. Teleconsultation in orthopaedic surgery: A systematic review and meta-analysis of patient and physician experiences. J Telemed Telecare. 2020 Sep.

8. Mooi JK, Whop LJ, Valery PC, Sabesan SS. Teleoncology for Indigenous patients: The responses of patients and health workers. Aust J Rural Health. 2012 Oct;20(5):265-9.

9. De Weger E, Macinnes D, Enser J, Francis SJ, Jones FW. Implementing video conferencing in mental health practice. J Psychiatr Ment Health Nurs. 2013 Apr;20(5):448-54. 
10. Hensel JM, Yang R, Vigod SN, Desveaux L. Videoconferencing at home for psychotherapy in the postpartum period: Identifying drivers of successful engagement and important therapeutic conditions for meaningful use. Couns Psychother Res. 2020.

11. Santoro SL, Donelan K, Haugen K, Oreskovic NM, Torres A, Skotko BG. Transition to virtual clinic: Experience in a multidisciplinary clinic for Down syndrome. Am J Med Genet C Semin Med Genet. 2021 Mar;187(1):70-82.

12. Dahl-Popolizio S, Carpenter H, Coronado M, Popolizio NJ, Swanson C. Telehealth for the provision of occupational therapy: Reflections on experiences during the COVID-19 pandemic. Int J Telerehabilitation. 2020;12(2):77-92.

13. Koch S, Guhres M. Physicians' experiences of patient-initiated online consultations in primary care using direct-to-consumer technology. Stud Health Technol Inform. 2020 Jun; 270:643-7.

14. World Health Organization. Coronavirus Disease (COVID-19) Situation Reports [Internet]. [cited 2021 Apr 9]. Available from: https://www.who.int/emergencies/diseases/novel-coronavirus-2019/situation-reports

15. Forbes P, Finch A. Redeployed staff and better teamwork: how COVID-19 has transformed nursing | RCNi [Internet]. Nursing Standard. 2020 [cited 2021 Apr 9]. Available from: https://rcni.com/nursingstandard/features/redeployed-staff-and-better-teamwork-how-covid-19-has-transformed-nursing-161911

16. Pandey N, Kaushal V, Puri GD, Taneja S, Biswal M, Mahajan P, et al. Transforming a General Hospital to an Infectious Disease Hospital for COVID-19 Over 2 Weeks. Front Public Health. 2020 Jul; 8:382-382.

17. Mehta S, Machado F, Kwizera A, Papazian L, Moss M, Azoulay É, et al. COVID-19: a heavy toll on health-care workers. Lancet Respir Med. 2021 Mar;9(3):226-8.

18. Grossman SN, Han SC, Balcer LJ, Kurzweil A, Weinberg H, Galetta SL, et al. Rapid implementation of virtual neurology in response to the COVID-19 pandemic. Neurology. 2020 Jun;94(24):1077-87.

19. Keesara S, Jonas A, Schulman K. Covid-19 and Health Care's Digital Revolution. N Engl J Med. 2020 Jun;382(23): e82-e82.

20. Chen JA, Chung WJ, Young SK, Tuttle MC, Collins MB, Darghouth SL, et al. COVID-19 and telepsychiatry: Early outpatient experiences and implications for the future. Gen Hosp Psychiatry. 2020 Sep; 66:89-95.

21. Lecomte T, Abdel-Baki A, Francoeur A, Cloutier B, Leboeuf A, Abadie P, et al. Group therapy via videoconferencing for individuals with early psychosis: A pilot study. Early Interv Psychiatry. 2020 Dec;15(6):15951601.

22. Tanaka MJ, Oh LS, Martin SD, Berkson EM. Telemedicine in the Era of COVID-19: The Virtual Orthopaedic Examination. J Bone Joint Surg Am. 2020 Jun;102(12):e57-e57.

23. Ganapathy K. Telemedicine and Neurological Practice in the COVID-19 Era. Neurol India. 2020 May;68(3):555-9.

24. Tarolli CG, Biernot JM, Creigh PD, Moukheiber E, Salas RME, Dorsey ER, et al. Practicing in a pandemic. Neurol Clin Pract. 2020 May;10. DOI:1212/CPJ.0000000000000882. 
25. Sutherland AE, Stickland J, Wee B. Can video consultations replace face-to-face interviews? Palliative medicine and the Covid-19 pandemic: Rapid review. BMJ Support Palliat Care. 2020 Sep;10(3):271-5.

26. Margusino-Framiñán L, Illarro-Uranga A, Lorenzo-Lorenzo K, Monte-Boquet E, Márquez-Saavedra E, Fernández-Bargiela N, et al. Author of correspondence Introduction: difficulties and objectives. 44:61-5.

27. Ghai S. Teledentistry during COVID-19 pandemic. Diabetes Metab Syndr Clin Res Rev. 2020 Sep;14(5):9335.

28. Chang CP, Lee TT, Mills ME. Experience of home telehealth technology in older patients with diabetes. CIN Comput Inform Nurs. 2017 Oct;35(10):530-7.

29. Appireddy R, Khan S, Leaver C, Martin C, Jin A, Durafourt BA, et al. Home virtual visits for outpatient followup stroke care: Cross-sectional study. J Med Internet Res [Internet]. 2019 Oct;21(10). Available from: /pmc/articles/PMC6803894/?report=abstract

30. Palcu P, Munce S, Jaglal SB, Allin S, Chishtie JA, Silverstein A, et al. Understanding patient experiences and challenges to osteoporosis care delivered virtually by telemedicine: a mixed methods study. Osteoporos Int. 2020 Feb;31(2):351-61.

31. Arksey H, O’Malley L. Scoping studies: Towards a methodological framework. Int J Soc Res Methodol Theory Pract. 2005 Feb;8(1):19-32.

32. Tricco AC, Lillie E, Zarin W, O’Brien KK, Colquhoun H, Levac D, et al. PRISMA Extension for Scoping Reviews (PRISMA-ScR): Checklist and Explanation. Ann Intern Med. 2018 Oct;169(7):467-467.

33. Adams J, Hillier-Brown FC, Moore HJ, Lake AA, Araujo-Soares V, White M, et al. Searching and synthesising "grey literature" and "grey information" in public health: Critical reflections on three case studies. Syst Rev. 2016 Sep;5(1):164-164.

34. Grey literature | Karolinska Institutet Universitetsbiblioteket [Internet]. [cited 2021 Apr 15]. Available from: https://kib.ki.se/en/search-evaluate/grey-literature

35. Zhang H, Cha EE, Lynch K, Cahlon O, Gomez DR, Shaverdian N, et al. Radiation Oncologist Perceptions of Telemedicine from Consultation to Treatment Planning: A Mixed-Methods Study. Int J Radiat Oncol Biol Phys. 2020 Oct;108(2):421-9.

36. Johnsson G, Kerslake R, Crook S. Delivering allied health services to regional and remote participants on the autism spectrum via video-conferencing technology: lessons learned. Rural Remote Health. 2019 Sep;19(3):53585358.

37. Fernemark H, Skagerström J, Seing I, Ericsson C, Nilsen P. Digital consultations in Swedish primary health care: a qualitative study of physicians' job control, demand and support. BMC Fam Pract. 2020 Dec;21(1).

38. Johnsen TM, Lønnebakke Norberg B, Kristiansen E, Zanaboni P, Austad B, Helgetun Krogh F, et al. Suitability of video consultations during the COVID-19 pandemic lockdown: Cross-sectional survey among Norwegian general practitioners. J Med Internet Res. 2021 Feb;23(2). 
39. Björndell C, Premberg Å. Physicians' experiences of video consultation with patients at a public virtual primary care clinic: a qualitative interview study. Scand J Prim Health Care. 2021;39(1):67-76.

40. Lechien JR, Radulesco T, Distinguin L, Chekkoury-Idrissi Y, Circiu MP, Afia FE, et al. Patient and otolaryngologist perceptions of telemedicine during COVID-19 pandemic. Eur Arch Otorhinolaryngol. 2021 Oct;278(10):4101-4105.

41. Dubin JM, Wyant WA, Balaji NC, Ong WLK, Kettache RH, Haffaf M, et al. Telemedicine Usage among Urologists during the COVID-19 Pandemic: Cross-Sectional Study. J Med Internet Res. 2020 Nov;22(11).

42. Vandekerckhove P, Vandekerckhove $\mathrm{Y}$, Tavernier R, de Jaegher $\mathrm{K}$, de Mul M. Leveraging user experience to improve video consultations in a cardiology practice during the COVID-19 pandemic: Initial insights. J Med Internet Res [Internet]. 2020 Jun;22(6). Available from: /pmc/articles/PMC7318925/?report=abstract

43. Kirby DJ, Fried JW, Buchalter DB, Moses MJ, Hurly ET, Cardone DA, et al. Patient and Physician Satisfaction with Telehealth During the COVID-19 Pandemic: Sports Medicine Perspective. Telemed E-Health. 2021 Oct; 27(10):1151-1159.

44. Tenforde AS, laccarino MA, Borgstrom H, Hefner JE, Silver J, Ahmed M, et al. Telemedicine During COVID-19 for Outpatient Sports and Musculoskeletal Medicine Physicians. PM R. 2020 Sep;12(9):926-32.

45. Cioffi V, Cantone D, Guerriera C, Architravo M, Mosca LL, Sperandeo R, et al. Satisfaction degree in the using of VideoConferencing Psychotherapy in a sample of Italian psychotherapists during Covid-19 emergency. In Institute of Electrical and Electronics Engineers Inc.; 2020. p. 125-32.

46. Hardy NR, Maier CA, Gregson TJ. Couple teletherapy in the era of COVID-19: Experiences and recommendations. J Marital Fam Ther. 2021 Apr; 47(2):225-43.

47. Sugarman DE, Horvitz LE, Greenfield SF, Busch AB. Clinicians' Perceptions of Rapid Scale-up of Telehealth Services in Outpatient Mental Health Treatment. Telemed E-Health. 2021 Dec;27(12):1399-1408.

48. Kemp MT, Liesman DR, Williams AM, Brown CS, lancu AM, Wakam GK, et al. Surgery Provider Perceptions on Telehealth Visits During the COVID-19 Pandemic: Room for Improvement. J Surg Res. 2021 Apr; 260:300-6.

49. Saiyed S, Nguyen A, Singh R. Physician Perspective and Key Satisfaction Indicators with Rapid Telehealth Adoption During the Coronavirus Disease 2019 Pandemic. Telemed E-Health. 2021 Nov;27(11):1225-1234.

50. Paulik G, Maloney G, Arntz A, Bachrach N, Koppeschaar A, McEvoy P. Delivering Imagery Rescripting via Telehealth: Clinical Concerns, Benefits, and Recommendations. Curr Psychiatry Rep. 2021 May;23(5).

51. Hinman RS, Nelligan RK, Bennell KL, Delany C. "Sounds a Bit Crazy, But It Was Almost More Personal:" A Qualitative Study of Patient and Clinician Experiences of Physical Therapist-Prescribed Exercise For Knee Osteoarthritis Via Skype. Arthritis Care Res. 2017 Dec;69(12):1834-44.

52. Mammen JR, Elson MJ, Java JJ, Beck CA, Beran DB, Biglan KM, et al. Patient and physician perceptions of virtual visits for Parkinson's disease: A qualitative study. Telemed E-Health. 2018 Apr;24(4):255-67. 
53. Barsom EZ, Jansen M, Tanis PJ, van de Ven AWH, Blussé van Oud-Alblas M, Buskens CJ, et al. Video consultation during follow up care: effect on quality of care and patient- and provider attitude in patients with colorectal cancer. Surg Endosc. 2021 Mar;35(3):1278-87.

54. Gold KJ, Laurie AR, Kinney DR, Harmes KM, Serlin DC. Video visits: Family physician experiences with uptake during the covid-19 pandemic. Fam Med. 2021 Mar;53(3):207-10.

55. Becevic M, Boren S, Mutrux R, Shah Z, Banerjee S. User satisfaction with telehealth: Study of patients, providers, and coordinators. Health Care Manag. 2015 Dec;34(4):337-49.

56. Rykkje L, Hjorth GHB. "Safety at Home”: Experiences From Testing of Video Communication Between Patients and Home Health Care Personnel. SAGE Open. 2017 Dec;7(4).

57. Heyer A, Granberg RE, Rising KL, Binder AF, Gentsch AT, Handley NR. Medical Oncology Professionals' Perceptions of Telehealth Video Visits. JAMA Netw Open. 2021 Jan;4(1): e2033967-e2033967.

58. Wade SL, Moscato EL, Raj SP, Narad ME. Clinician perspectives delivering telehealth interventions to children/families impacted by pediatric traumatic brain injury. Rehabil Psychol. 2019 Aug;64(3):298-306.

59. Levy S, Mason S, Russon J, Diamond G. Attachment-based family therapy in the age of telehealth and COVID-19. J Marital Fam Ther. 2021 Apr;47(2):440-54.

60. Békés V, Aafjes-van Doorn K, Prout TA, Hoffman L. Stretching the Analytic Frame: Analytic Therapists' Experiences with Remote Therapy During COVID-19. J Am Psychoanal Assoc. 2020 Jun;68(3):437-46.

61. Yu J, Afridi SM, Cozart AC, Isea L, Guan J. Evaluation and Feedback for Telehealth From Patients and Physicians During the Early Stage of COVID-19 Pandemic Period. Cureus. 2021 Jan 11;13(1): e12633.

62. Combi C, Pozzani G, Pozzi G. Telemedicine for developing countries: A survey and some design issues. Appl Clin Inform. 2016 Nov;7(4):1025-50.

63. Downs J, Lotan M, Elefant C, Leonard H, Wong K, Buckley N, et al. Implementing telehealth support to increase physical activity in girls and women with Rett syndrome-ActivRett: protocol for a waitlist randomised controlled trial. BMJ OPEN. 2020;10(12).

64. Johansson AM, Lindberg I, Söderberg S. Healthcare personnel's experiences using video consultation in primary healthcare in rural areas. Prim Health Care Res Dev. 2017 Jan;18(1):73-83.

65. Managing Remote Workers: Preventing Isolation and Loneliness [Internet]. [cited 2021 May 13]. Available from: https://www.consultdss.com/preventing-isolation-and-loneliness/

66. Bradford NK, Penny RA. Registered nurse and midwife experiences of using videoconferencing in practice: a qualitative systematic review protocol. JBI Database Syst Rev Implement Rep. 2016 May;14(5):3-9.

67. Pidgeon FM. Use of telehealth videoconferencing as a supplement to visiting allied health services. Aust $J$ Rural Health. 2017 Feb;25(1):58-9.

68. Lovo S, Harrison L, O'Connell ME, Trask C, Bath B. Experience of patients and practitioners with a team and technology approach to chronic back disorder management. J Multidiscip Healthc. 2019 Oct 18;12:855-69. 
69. Uscher-Pines L, Sousa J, Raja P, Mehrotra A, Barnett ML, Huskamp HA. Suddenly becoming a “Virtual doctor": Experiences of psychiatrists transitioning to telemedicine during the COVID-19 pandemic. Psychiatr Serv. 2020 Nov;71(11):1143-50.

70. Yang L, Brown-Johnson CG, Miller-Kuhlmann R, Kling SMR, Saliba-Gustafsson EA, Shaw JG, et al. Accelerated launch of video visits in ambulatory neurology during COVID-19: Key lessons from the Stanford experience. Neurology. 2020 Aug;95(7):305-11.

71. Munn Z, Peters MDJ, Stern C, Tufanaru C, McArthur A, Aromataris E. Systematic review or scoping review? Guidance for authors when choosing between a systematic or scoping review approach. BMC Med Res Methodol. 2018 Nov;18(1):143-143.

72. Clarke V, Braun V. Thematic analysis. J Posit Psychol. 2017 May;12(3):297-8.

\section{Figures}
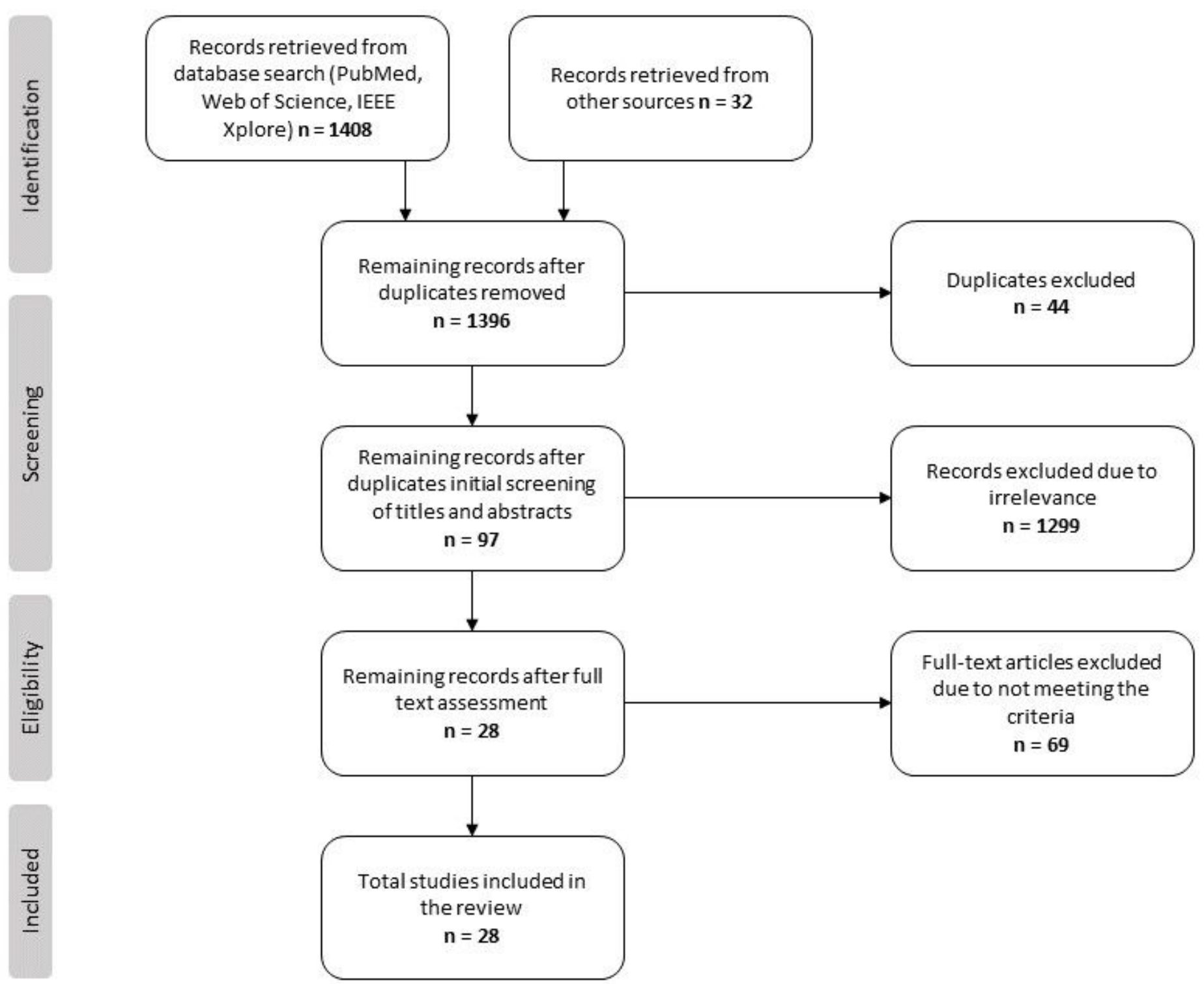

Figure 1 
The process of study selection - Preferred Reporting Items for Systematic reviews and Meta-Analyses (PRISMA) flow chart 